\title{
To Study the Association of Parathyroid Hormone with Severe Anaemia in Chronic Renal Failure Patients
}

\author{
Madhavi Sarkari ${ }^{1}$, Mahim Mittal² ${ }^{2}$ Ashutosh Kumar Rai ${ }^{3}$ \\ 1, 2,3 Department of Medicine, Baba Raghav Das Medical College, Gorakhpur, Uttar Pradesh, India.
}

\section{ABSTRACT}

\section{BACKGROUND}

Chronic kidney disease is defined as abnormalities of kidney structure or function, present for $>3$ months, with implications for health. In India, the prevalence of chronic kidney disease (CKD), ranges from $0.79 \%$ to $1.4 \%$. Secondary hyperparathyroidism (SHPT) is one of the less recognized reasons of anaemia in chronic kidney disease (CKD). In this study, we evaluated the role of SHPT as a cause of anaemia, and correlation of intact parathyroid hormone (iPTH) and haemoglobin (Hb) levels in chronic renal failure (CRF) patients on haemodialysis and also in CRF patients who are not on haemodialysis.

\section{METHODS}

This is an observational cross-sectional study done in the department of medicine in BRD Medical College, Gorakhpur, Uttar Pradesh, India, over a period of one year among a total of 101 patients. All patients underwent detailed clinical history, clinical examination \& relevant biochemical investigations.

\section{RESULTS}

Parathyroid hormone level was found elevated in $82.2 \%$ CRF patients in our study; out of these $76.2 \%$ patients were severely anaemic.

\section{CONCLUSIONS}

Anaemia mainly normocytic \& normochromic is a common complication of chronic kidney disease. Hormonal failure in CRF patients is very commonly reflected as anaemia \& mineral and bone disorder (CKD-MBD). Parathyroid hormone was found elevated in most (82.2 \%) of the CRF patients with anaemia.

\section{KEY WORDS}

Chronic Renal Failure (CRF), Intact Parathyroid Hormone (iPTH), Secondary Hyperparathyroidism (SHPT), Chronic Kidney Disease (CKD)
Corresponding Author: Dr. Ashutosh Kumar Rai, Department of Medicine, BRD Medical College, Gorakhpur, Uttar Pradesh, India.

E-mail: rai.ashutosh02@gmail.com

DOI: $10.14260 /$ jemds/2021/155

How to Cite This Article:

Sarkari M, Mittal M, Rai AK. To study the association of parathyroid hormone with severe anaemia in chronic renal failure patients. J Evolution Med Dent Sci 2021;10(10):724-728, DOI: 10.14260/jemds/2021/155

Submission 27-04-2020,

Peer Review 14-01-2021,

Acceptance 20-01-2021,

Published 08-03-2021.

Copyright (C) 2021 JEMDS. This is an open access article distributed under Creative Commons Attribution License [Attribution 4.0 International (CC BY 4.0)] 


\section{BACKGROUND}

Chronic kidney disease (CKD) is defined as functional abnormalities of the kidney lasting longer than 3 months, with or without reduced glomerular filtration rate. It can also be defined by the presence of urinary albumin with an excretion rate higher than $300 \mathrm{mg} / 24 \mathrm{~h}$ or in a ratio of more than 200 $\mathrm{mg}$ of albumin to $1 \mathrm{~g}$ of creatinine. In India the prevalence of CKD ranges from $0.79 \%$ to $1.4 \%$. CKD is divided into 5 stages on the basis of estimated glomerular filtration rate (eGFR). Stages 1 and 2 CKD are usually not associated with any symptoms arising from the decrement in GFR. If the decline in GFR progresses to stages 3 and 4 clinical and laboratory complications of CKD become prominent. On the basis of albuminuria, CKD is divided into 3 stages depending on amount of albumin excreted in urine. Uremia leads to disturbances in the function of virtually every organ system in the body. The World Health Organization defines anaemia as a haemoglobin level less than $13 \mathrm{~g} / \mathrm{dL}$ in men and postmenopausal women, and less than $12 \mathrm{~g} \mathrm{/} \mathrm{dL}$ in premenopausal women. (WHO 1968). According to National Kidney Foundation a haemoglobin of less than $13.5 \mathrm{~g} / \mathrm{dL}$ in men and less than $12.0 \mathrm{~g} / \mathrm{dL}$ in women is considered as anaemia (NKF KDOQI 2006). Anaemia is very common mainly normochromic, normocytic in CKD patients, overall prevalence is around $50 \%$. Anaemia in CKD is due to multiple mechanisms: Relative deficiency of erythropoietin, diminished red blood cell survival, bleeding diathesis, chronic inflammation, hyperparathyroidism, haemoglobinopathy, hepcidin excess, comorbid conditions - hypo / hyperthyroidism, pregnancy, HIV, autoimmune disease and immunosuppressive drugs.

The diagnosis of anaemia of chronic renal failure rests on the presence of normochromic, normocytic anaemia with, normal leukocyte and platelet counts, coupled with, iron sufficiency (transferrin saturation $>20 \%$ and serum ferritin level > $100 \mathrm{ng} / \mathrm{mL}$ ), low absolute reticulocyte count and rapid response to erythropoietin therapy within 4 weeks confirms diagnosis. ${ }^{1}$ Management of anaemia in CKD was revolutionized by introduction of ESA (erythrocyte stimulating agents). ESA stimulate erythroid proliferation and differentiation, improve haematocrit and haemoglobin levels, and reduce the need for transfusions. Side effects such as worsening of hypertension, seizures and dialysis access clotting may occur. They do not reduce adverse outcomes associated with anaemia such as mortality, nonfatal cardiovascular events, left ventricular hypertrophy (LVH), hospitalizations and progression of CKD. Recent studies have described osteoblasts as an important promoter of haematopoiesis. ${ }^{2,3}$ In diabetic CKD, depressed number of osteoblasts results in impaired haematopoiesis, higher PTH levels seems to be protective against this. Due to osteoblastspecific constitutive activation of the PTH receptors, an expansion of haematopoietic stem cells in vivo occurs possibly via the insulin growth factor (IGF) pathway.., 5

Erythropoiesis may be affected by IGF-1 through different pathways. Similar to erythropoietin, IGF-1 inhibits apoptosis of erythroid progenitor cell, in addition proliferation of erythroid progenitor cells at maturity level may be accelerated by IGF-1.

The diabetic CKD patients have lower level of IGF-1 than CKD patients without diabetes and hence result in increased chances of anaemia in diabetic CKD patients. Thus, increased PTH levels may result in raised level of IGF-1 levels in diabetics, this indeed leads to higher haemoglobin level. ${ }^{6}$

\section{METHODS}

This observational cross-sectional study was conducted in 101 CRF patients (as per KDIGO [Kidney Disease Improving Global Outcomes] guidelines) ${ }^{7}$ attending the OPD \&/or admitted in medicine ward of Department of Medicine, at B. R. D. Medical College Gorakhpur, Uttar Pradesh, India over the period of one year. The study was approved by ethics committee and informed consent was obtained. The sample size was taken based on the convenience of the study.

We excluded patients with anaemia due to chronic disease other than CRF, patients with sarcoidosis, paraneoplastic syndrome \& patients with primary hyperparathyroidism. Total $101 \mathrm{CRF}$ patients were recruited according to inclusion \& exclusion criteria.

All patients were interviewed after written informed consent regarding detailed clinical history e.g. history of present illness, past history, personal history \& symptoms. A thorough clinical examination including general physical examination, vitals (pulse rate, blood pressure, and respiratory rate) \& systemic examination was carried out.

All selected CRF patients were also subjected to estimation of serum iPTH, serum creatinine, serum ferritin, serum calcium, serum phosphorus, $\mathrm{HbA}_{1} \mathrm{C}$ and urine routine microscopy.

\section{Statistical Analysis}

The statistical package for social science $\{$ SPSS $\}$ version 20 will be used for data analysis. Mean, median, and standard deviation (SD) are used to describe quantitative data. Qualitative data are summarized using frequency and percentage.

\section{RESULTS}

Our study group consist of $101 \mathrm{CRF}$ patients, out of which 58 patients were male and 43 patients were female. The risk of CKD progression is closely linked to both GFR and amount of albuminuria, staging of CKD stratified by both of these parameters. Most of cases in this study were in stage 5 (86.14 $\%$ ). The patients included in study were in age group $40-80$ years. Out of total 101 population 58 males \& 43 females were included in our study.

Table 1. Shows the \% age of cases according to stages of CKD in CRF patients with anaemia. Most of cases were in stage $5(86.14 \%)$ followed by stage $4(12.87 \%)$ and only few percent in stage $3 \mathrm{~b}(0.9 \%)$.

Table 3A. Shows the association of level of parathyroid hormone in CRF patients with anaemia with age. About one third of patients were $<40$ years of age $(31.7 \%)$ followed by 
$51-60(24.8 \%),>60(22.8 \%)$ and $40-50(20.8 \%)$ years. The level of parathyroid hormone was highest in age $>60$ years $(87$ $\%)$ and was lowest in $40-50$ years (76.2\%). There was no significant $(p>0.05)$ association of level of parathyroid hormone in CRF patients with anaemia with age.

Table 3B. Shows the association of level of parathyroid hormone in CRF patients with anaemia with gender. More than half of patients were males (57.4\%).

The level of parathyroid hormone was higher among males $(89.7 \%)$ than females $(72.1 \%)$. There was significant $(\mathrm{p}=$ 0.02) association of level of parathyroid hormone in CRF patients with anaemia with gender.

\begin{tabular}{|ccc|}
\hline Stage of CKD & No. of Cases & Percentage \\
Stage 1 (eGFR > 90 \%) & 0 & $0 \%$ \\
Stage 2 (eGFR 60 - 89 \%) & 0 & $0 \%$ \\
Stage 3a (eGFR 45 - 59\%) & 0 & $0 \%$ \\
Stage 3b (eGFR 30 - 44\%) & 1 & $0.9 \%$ \\
Stage 4 (eGFR 15 - 29\%) & 13 & $12.87 \%$ \\
Stage 5 (eGFR < 15 \%) & 87 & $86.14 \%$ \\
Total & $\mathbf{1 0 1}$ & $\mathbf{1 0 0 . 0 0 ~ \% ~}$ \\
\hline Table 1. Cases According to the Stage of CKD \\
\hline
\end{tabular}

\begin{tabular}{|ccr|}
\hline Level of Parathyroid Hormone & No. (n = 101) & $\%$ \\
Increased & 83 & 82.2 \\
Normal & 18 & 17.8 \\
\hline $\begin{array}{c}\text { Table 2. Level of Parathyroid Hormone in CRF Patients with Anaemia. } \\
\text { Increased Level of Parathyroid Hormone in CRF Patients } \\
\text { with Anaemia was } 82.2 \%\end{array}$ \\
\hline
\end{tabular}

\begin{tabular}{|c|c|c|c|c|c|c|c|}
\hline \multirow{3}{*}{ Age in Years } & \multirow{2}{*}{\multicolumn{2}{|c|}{ No. of Patients }} & \multicolumn{4}{|c|}{ Level of Parathyroid Hormone } & \multirow{3}{*}{$\begin{array}{c}\text { P- } \\
\text { Value }^{1}\end{array}$} \\
\hline & & & \multicolumn{2}{|c|}{ Increased } & \multicolumn{2}{|c|}{ Normal } & \\
\hline & No. & $\%$ & No. & $\%$ & No. & $\%$ & \\
\hline$<40$ & 32 & 31.7 & 26 & 81.2 & 6 & 18.8 & \multirow{4}{*}{0.81} \\
\hline $40-50$ & 21 & 20.8 & 16 & 76.2 & 5 & 23.8 & \\
\hline $51-60$ & 25 & 24.8 & 21 & 84.0 & 4 & 16.0 & \\
\hline$>60$ & 23 & 22.8 & 20 & 87.0 & 3 & 13.0 & \\
\hline \multicolumn{8}{|c|}{${ }^{1}$ Chi-square test } \\
\hline \multicolumn{8}{|c|}{$\begin{array}{l}\text { 3A. Association of Level of Parathyroid Hormone in CRF Patients with } \\
\text { Anaemia and Age }\end{array}$} \\
\hline \multirow[t]{2}{*}{ Gender } & \multicolumn{2}{|c|}{ No. of patients } & \multicolumn{4}{|c|}{ Level of Parathyroid Hormone } & p-Value ${ }^{1}$ \\
\hline & No. & $\%$ & No. & $\%$ & No. & $\%$ & \\
\hline Male & 58 & 57.4 & 52 & 89.7 & 6 & 10.3 & $0.02 *$ \\
\hline Female & 43 & 42.6 & 31 & 72.1 & 12 & 27.9 & \\
\hline \multicolumn{8}{|c|}{$\begin{array}{l}\text { 3B. Association of Level of Parathyroid Hormone in CRF Patients with } \\
\text { Anaemia and Gender }\end{array}$} \\
\hline \multicolumn{8}{|c|}{ Table 3} \\
\hline -squa & $* \mathrm{~s}$ & & & & & & \\
\hline
\end{tabular}

\begin{tabular}{|c|c|c|c|c|c|c|c|c|}
\hline \multirow{3}{*}{$\begin{array}{l}\text { Haemodialysis / } \\
\text { Not on } \\
\text { Haemodialysis }\end{array}$} & \multirow{2}{*}{\multicolumn{2}{|c|}{$\begin{array}{c}\text { No. of } \\
\text { Patients }\end{array}$}} & \multicolumn{5}{|c|}{$\begin{array}{l}\text { Level of Parathyroid Hormone } \\
\text { Elevation }\end{array}$} & \multirow{3}{*}{$\begin{array}{c}\text { P- } \\
\text { Value }^{1}\end{array}$} \\
\hline & & & \multicolumn{3}{|c|}{ Increased } & \multicolumn{2}{|c|}{ Normal } & \\
\hline & No. & $\%$ & \multicolumn{2}{|c|}{ No. } & $\%$ & \multicolumn{2}{|c|}{ No. $\%$} & \\
\hline On haemodialysis & 40 & 39.6 & 3 & & 90.0 & 4 & 10.0 & \multirow[b]{2}{*}{0.09} \\
\hline $\begin{array}{c}\text { not on } \\
\text { Haemodialysis }\end{array}$ & 61 & 60.4 & \multicolumn{2}{|c|}{47} & 77.0 & 14 & 23.0 & \\
\hline \multicolumn{9}{|c|}{ chi-square test } \\
\hline \multicolumn{9}{|c|}{$\begin{array}{c}\text { 4A. Association of Level of Parathyroid Hormone in CRF Patients with } \\
\text { Anaemia on Haemodialysis \& Not on Haemodialysis }\end{array}$} \\
\hline \multirow[t]{2}{*}{ Hypertension } & \multirow{2}{*}{\multicolumn{2}{|c|}{$\begin{array}{c}\text { No. of } \\
\text { Patients }\end{array}$}} & \multirow{2}{*}{\multicolumn{2}{|c|}{$\begin{array}{l}\text { evel of Parathy } \\
\text { Elevat } \\
\text { Increased }\end{array}$}} & $\begin{array}{l}\text { rroid } \mathrm{H} \\
\text { tion }\end{array}$ & rmone & \multirow{2}{*}{\multicolumn{2}{|c|}{ P-Value ${ }^{1}$}} \\
\hline & & & & & \multicolumn{2}{|c|}{ Normal } & & \\
\hline Hypertensive & $\begin{array}{c}\text { No. } \\
57\end{array}$ & $\begin{array}{c}\% \\
56.4\end{array}$ & $\begin{array}{l}\text { No. } \\
47\end{array}$ & $\begin{array}{c}\% \\
82.5\end{array}$ & $\begin{array}{r}\text { No } \\
10\end{array}$ & $\begin{array}{c}\% \\
17.5\end{array}$ & & 0.93 \\
\hline Normotensive & 44 & 43.6 & 36 & 81.8 & 8 & 18.2 & & \\
\hline \multicolumn{9}{|c|}{$\begin{array}{l}\text { 4B. Association of Level of Parathyroid Hormone in CRF Patients with } \\
\text { Anaemia with Hypertension }\end{array}$} \\
\hline \multicolumn{9}{|c|}{ Table 4} \\
\hline$-s q$ & & & & & & & & \\
\hline
\end{tabular}

Table 4A. Shows the association of level of parathyroid hormone in CRF patients with anaemia on haemodialysis \& not on haemodialysis. $39.6 \%$ patients were on haemodialysis.
The level of parathyroid hormone in CRF patients with anaemia was higher among patients those on haemodialysis. There was no significant ( $p>0.05$ ) association of level of parathyroid hormone in CRF patients with anaemia with haemodialysis.

Table 4B. shows the association of level of parathyroid hormone in CRF patients with anaemia with hypertension. Hypertension was present among $56.4 \%$ patients. The level of parathyroid hormone in CRF patients with anaemia was higher among whom hypertension was present. There was no significant ( $p>0.05$ ) association of level of parathyroid hormone in CRF patients with anaemia with hypertension.

\begin{tabular}{|c|c|c|c|c|c|c|c|}
\hline \multirow{3}{*}{$\begin{array}{l}\text { Diabetes } \\
\text { Mellitus }\end{array}$} & \multirow{2}{*}{\multicolumn{2}{|c|}{ No. of Patients }} & \multicolumn{4}{|c|}{$\begin{array}{l}\text { Level of Parathyroid Hormone } \\
\text { Elevation }\end{array}$} & \multirow{3}{*}{$\begin{array}{c}\text { P- } \\
\text { Value }^{1}\end{array}$} \\
\hline & & & \multicolumn{2}{|c|}{ Increased } & \multicolumn{2}{|c|}{ Normal } & \\
\hline & No. & $\%$ & No. & $\%$ & No. & $\%$ & \\
\hline Diabetic & 36 & 35.6 & 30 & 83.3 & 6 & 16.7 & \multirow{2}{*}{0.82} \\
\hline Non diabetic & 65 & 64.4 & 53 & 81.5 & 12 & 18.5 & \\
\hline \multicolumn{8}{|c|}{$\begin{array}{c}\text { 5A. Association of Level of Parathyroid Hormone in CRF Patients with } \\
\text { Anaemia and Diabetes }\end{array}$} \\
\hline \multirow{3}{*}{$\begin{array}{c}\text { Severity of } \\
\text { Anaemia }\end{array}$} & \multicolumn{2}{|c|}{ No. of Patients } & \multicolumn{4}{|c|}{ Parathyroid Hormone } & \multirow{6}{*}{$\begin{array}{c}\text { P-Value } \\
1\end{array}$} \\
\hline & & & \multicolumn{2}{|c|}{ Increased } & \multicolumn{2}{|c|}{ Normal } & \\
\hline & No. & $\%$ & No. & $\%$ & No. & $\%$ & \\
\hline Mild & 2 & 2.0 & 2 & 100. & 0 & 0.0 & \\
\hline Moderate & 22 & 21.8 & 19 & 86.4 & 3 & 13.6 & \\
\hline Severe & 77 & 76.2 & 62 & 80.5 & 15 & 19.5 & \\
\hline \multicolumn{8}{|c|}{$\begin{array}{l}\text { 5B. Association of Level of Parathyroid Hormone in CRF Patients with } \\
\text { Anaemia and Severity of Anaemia }\end{array}$} \\
\hline \multicolumn{8}{|c|}{ Table 5} \\
\hline${ }^{1}$ Chi-sc & & & & & & & \\
\hline
\end{tabular}

Table 5A. Shows the association of level of parathyroid hormone in CRF patients with anaemia with diabetes. Diabetes was present among $35.6 \%$ patients. The level of parathyroid hormone in CRF patients with anaemia was higher among whom diabetes was present. There was no significant $(\mathrm{p}>$ 0.05) association of level of parathyroid hormone in CRF patients with anaemia with diabetes.

Table 5B. Shows the association of level of parathyroid hormone in CRF patients with anaemia with severity of anaemia. Severe anaemia was among majority of patients (76.2\%). There was no significant $(\mathrm{p}>0.05)$ association of level of parathyroid hormone in CRF patients with anaemia with severity of anaemia.

\begin{tabular}{|cccc|}
\hline Biochemical Parameters & $\begin{array}{c}\text { Level of Parathyroid Hormone } \\
\text { Increased } \\
\text { Normal }\end{array}$ & P-Value \\
& $134.11 \pm 6.57$ & $132.56 \pm 5.99$ & 0.35 \\
Serum Na+ & $5.17 \pm 0.72$ & $5.14 \pm 0.93$ & 0.86 \\
Serum K+ & $6.76 \pm 1.66$ & $6.60 \pm 1.02$ & 0.69 \\
Serum $\mathrm{PO}_{4}$ & $6.55 \pm 1.51$ & $6.01 \pm 1.18$ & 0.15 \\
$\mathrm{HbA1c}^{\text {Serum creatinine }}$ & $10.80 \pm 5.74$ & $9.79 \pm 6.30$ & 0.51 \\
BUN & $96.91 \pm 37.01$ & $103.77 \pm 33.23$ & 0.47 \\
Serum urea & $194.94 \pm 88.65$ & $194.81 \pm 83.38$ & 0.99 \\
Serum calcium & $7.87 \pm 1.79$ & $8.73 \pm 1.72$ & 0.06 \\
Serum Vitamin D & $21.12 \pm 8.46$ & $21.73 \pm 9.46$ & 0.78 \\
Hb & $7.08 \pm 1.44$ & $6.75 \pm 1.25$ & 0.36 \\
Serum ferritin & $373.01 \pm 286.11$ & $210.83 \pm 248.29$ & $0.02^{*}$ \\
\hline Table 6. Comparison of Biochemical Parameters with Level of \\
Parathyroid Hormone in CRF Patients with Anaemia \\
\hline${ }^{1}$ Unpaired t-test, *Significant \\
\hline
\end{tabular}

Table 6. Shows the comparison of biochemical parameters with parathyroid hormone in CRF patients with anaemia. There was no significant ( $p>0.05$ ) difference in biochemical parameters between patients with and without parathyroid hormone elevation, however, a statistically significant 
increase in serum ferritin level was found in association with increased level of parathyroid.

\section{DISCUSSION}

Present institutional observational cross-sectional study was done in the Department of Medicine, BRD Medical College Gorakhpur over a period of one year to evaluate the association of parathyroid hormone with severe anaemia in CRF patients. Our study group consist of $101 \mathrm{CRF}$ patients, out of which 58 patients were male and 43 patients were female. All patients included in study were who visited in OPD \& / or admitted in medicine ward according to their symptoms, signs \& lab investigations. The risk of CKD progression is closely linked to both GFR and amount of albuminuria, staging of CKD stratified by both of these parameters. ${ }^{7,8}$ Most of cases in study were in stage $5(86.14 \%)$. The patients included in our study were in age group 40 - 80 years. Out of total 101 population 58 males \& 43 females were included in our study.

In our study, the parathyroid level was found higher among men (89.7\%) as compared to women (72.1\%), it reveals the gender difference in PTH elevation among CRF patients and it was found statistically significant, this is in contrast to study of Yudan Wei et al. ${ }^{50}$ in which elevated PTH was more commonly observed in female than in male. The gender difference in the development of SHPT may be explained by up regulation of the mRNA expression levels of PTH in parathyroid cells 50 mediated via elevated oestrogen and oestrogen receptor expression. The result in our study differ from Yudan Wei et al. ${ }^{50}$ may be due to short sample size \& comparatively a greater number of males in the study. Parathyroid hormone was elevated in 83 cases (82.2\%) \& was normal in 18 cases (17.8\%). In our study parathyroid hormone level was highest among in age group $>60$ years (87 $\%) \&$ was lowest in 40 - 50-year age group (76.2 \%); however, there was no significant association ( $p>0.05 \%$ ) of level of parathyroid hormone elevation in CRF patients with age. Study done by Happy Chutiya et al. also supported my findings that level of parathyroid hormone was increasing as age increases, however, he also found that parathyroid hormone elevation was not statistically significant. Our study showed that parathyroid level was higher among CRF patients with anaemia who were on haemodialysis, however, it was not significant, this is similar to study done by Potorio G. et al. About $39.6 \%$ patients of CRF with anaemia were on haemodialysis in our study. According to Yudan Wei et al. hypertension is a common complication of CKD and this is also a major risk factor for CKD. As the CKD progresses, chances of hypertension in CRF patients' increases, about $80-85 \%$ patients of advanced CRF had hypertension. Our findings showed that $82.5 \%$ patients with CKD had hypertension, and the majority of these hypertensive patients had increased level of parathyroid hormone but not statistically significant. Elevation of PTH levels in patients of CKD promotes vascular contraction via increase in cytoplasmic calcium concentration in vascular smooth muscle cells, as explained in a previous study. In our study, $35.6 \%$ of CRF patients with anaemia were diabetic, level of parathyroid hormone was higher in diabetic CRF patients, however there was no statistically significant association found between parathyroid hormone elevation and diabetes. This is similar to study done by Shoichiro Nagasaka et al. which showed that parathyroid level was higher among diabetic patients. IGF-1 may affect erythropoiesis via different pathways contributing to the anaemia of CKD in diabetes. Similar to erythropoietin, IGF-1 inhibits apoptosis of erythroid progenitor cell, in addition proliferation of erythroid progenitor cells at maturity level may be accelerated by IGF-1. The diabetic CKD patients have lower level of IGF-1 than CKD patients without diabetes and hence results in increased chances of anaemia in diabetic CKD patients. Thus, increased PTH levels may result in raised level of IGF-1 levels in diabetics, indeed leads to higher haemoglobin level.9,10,11

In a study done by Happy Chutia et al. ${ }^{51}$ it is shown that there is linear relation between level of parathyroid and serum ferritin, however, it was not significant. In our study statistically significant association between parathyroid level and serum ferritin level was found, it showed increased parathyroid level was associated with modest increase in serum ferritin level. Anaemia is a common complication of chronic kidney disease (CKD). There are various causes of anaemia in CKD such as decreased production of erythropoietin (EPO), resistance to EPO, shortened survival of red blood cells (RBCs), and bone marrow fibrosis. Secondary hyperparathyroidism (SHPT) is a less recognized, but potentially significant cause of renal anaemia in CKD patients. ${ }^{12,13}$ Parathyroid hormone (PTH) has been regarded as a uremic toxin that potentially inhibits EPO synthesis, shortens the survival of RBCs, and causes myelofibrosis and thereby decreases haematopoietis. ${ }^{14}$ Our study examines the association of PTH with anaemia in 101 samples of CRF patients both on haemodialysis \& not on haemodialysis. Out of 101 patients in our study, 77 patients $(76.2 \%)$ were severely anaemic. Patients with CRF and anaemia have poorer outcomes and an impaired quality of life; anaemia is significant contributor to both.

We did not record folate, vitamin B12, and iron levels which seems to be important confounder in this study. Iron may be an important regulator of fibroblast growth factor-23 (FGF-23) \& thereby may regulate PTH secretion. Adjusting for the effects of iron and / or FGF-23 would enhance our study.

It is generally thought that hypocalcaemia is as a result of phosphate retention and deficient vitamin D synthesis. In response to an increase in serum phosphorus concentration, production of vitamin $\mathrm{D}$ is decreased and secretion of parathyroid hormone (PTH) is increased, which, in turn, increases urinary excretion of serum phosphorus to maintain normal serum calcium and phosphorus level. Therefore, PTH is an important factor in the regulation of calcium, magnesium, and phosphorus metabolism. In our study an inverse linear relation was found between parathyroid level \& serum calcium level however it was not statistically significant. This is similar to study of Kirti Arora et al. except that it was statistically significant.

However, there are several limitations of our study such as cross-sectional nature of this study, the lack of important confounders, both known and unknown ones, limits the conclusions of an independent effect of PTH, misclassification bias in the results due to single measurements of both the predictor and main outcome, the relative change in haemoglobin per change in PTH was rather modest and may be within the normal variability of the assay. 


\section{CONCLUSIONS}

The risk of CKD progression is closely linked to both GFR and extent of albuminuria. Staging of CKD is done using both these parameters. Most of cases in our study were in stage 5 . Anaemia mainly normocytic \& normochromic is a common complication of chronic kidney disease. Hormonal failure in CRF patients is very commonly reflected by anaemia \& mineral and bone disorder (CKD-MBD). Parathyroid hormone level was found elevated in most (82.2\%) of the CRF patients with anaemia in our study. A statistically non-significant association was found between the level of parathyroid hormone \& severity of anaemia. About $76.2 \%$ patients had severe anaemia in our study. Level of parathyroid hormone was found higher among elderly males (89.7 \%) in our study which was statistically significant. Hypertension is a risk factor of CKD and also a common complication of CKD.

Data sharing statement provided by the authors is available with the full text of this article at jemds.com.

Financial or other competing interests: None.

Disclosure forms provided by the authors are available with the full text of this article at jemds.com.

\section{REFERENCES}

[1] Kidney Disease: Improving global outcomes (KDIGO) CKD work group. KDIGO 2012 clinical practice guideline for the evaluation and management of chronic kidney disease. Kidney Inter Suppl 2013;3(1):1-150.

[2] Goodman WG, Jüppner H, Salusky IB, et al. Parathyroid hormone (PTH), PTH-derived peptides and new PTH assays in renal osteodystrophy. Kidney Int 2003;63(1):111.

[3] Kidney Disease: improving global outcomes. KDIGO clinical practice guideline for the diagnosis, evaluation, prevention and treatment of chronic kidney diseasemineral and bone disorder (CKD-MBD). Kidney International 2009;76(Suppl 113):S1.

[4] Wei Y, Lin J, Yang F, et al. Risk factors associated with secondary hyperparathyroidism in patients with chronic kidney disease. Exp Ther Med 2016;12(2):1206-12.
[5] Chutia H, Ruram A, Bhattacharyya H, et al. Association of secondary hyperparathyroidism with haemoglobin level in patients with chronic kidney disease. J Lab Physicians 2013;5(1):51-4.

[6] Bargman JM, Skorecki K. Chronic Kidney disease. In: Fauci AS, Kasper DL, Hauser SL, et al. Harrison' principles of internal medicine. 19th edn. NewYork: McGraw Hill 2015:1811-21.

[7] Brancaccio D, Cozzolino M, Gallieni M. Hyperparathyroidism and anaemia in uremic subjects: a combined therapeutic approach. J Am Soc Nephrol 2004;15(Suppl 1):S21-4.

[8] Rao DS, Shih MS, Mohini R. Effect of serum parathyroid hormone and bone marrow fibrosis on the response to erythropoietin in uremia. N Engl J Med 1993;328(3):1715.

[9] Urena P, Eckardt KU, Sarfati E, et al. Serum erythropoietin and erythropoiesis in primary and secondary hyperparathyroidism: effect of parathyroidectomy. Nephron 1991;59(3):384-93.

[10] Memon I, Norris KC, Bomback AS, et al. The association between parathyroid hormone levels and haemoglobin in diabetic and nondiabetic participants in the national kidney foundation's kidney early evaluation program. Cardiorenal Med 2013;3(2):120-7.

[11] Durham BH, Joseph F, Bailey LM, et al. The association of circulating ferritin with serum concentrations of fibroblast growth factor-23 measured by three commercial assays. Ann Clin Biochem 2007;44(Pt 5):4636.

[12] Ben-Dov IZ, Galitzer H, Lavi-Moshayoff V, et al. The parathyroid is a target organ for FGF23 in rats. J Clin Invest 2007;117(12):4003-8.

[13] Yoda K, Imanishi Y, Yoda M, et al. Impaired response of FGF-23 to oral phosphate in patients with type 2 diabetes: a possible mechanism of atherosclerosis. J Clin Endocrinol Metab 2012;97(11):E2036-43.

[14] Sonkar SK, Singh HP, Sonkar GK, et al. Association of vitamin $\mathrm{D}$ and secondary hyperparathyroidism with anaemia in diabetic kidney disease. J Fam Med Prim Care 2018;7(4):815-8. 